\title{
Factors That Affect Teachers' Coping with Cyberbullying: Implications for Teacher Education Programs
}

\author{
Dorit Olenik-Shemesh ${ }^{1 *}$, Tali Heiman1, Noam Semy Keshet ${ }^{2}$ \\ ${ }^{1}$ Education and Psychology Department, The Open University of Israel, Ra'anana, Israel \\ ${ }^{2}$ School of Business Administration, The Hebrew University, Jerusalem, Israel \\ Email: ^doritol@openu.ac.il, talihe@openu.ac.il,keshet.noam@gmail.com
}

How to cite this paper: Olenik-Shemesh, D., Heiman, T., \& Keshet, N. S. (2019). Factors That Affect Teachers' Coping with Cyberbullying: Implications for Teacher Education Programs. Creative Education, 10, 3357-3371.

https://doi.org/10.4236/ce.2019.1013258

Received: November 13, 2019

Accepted: December 10, 2019

Published: December 13, 2019

Copyright $\odot 2019$ by author(s) and Scientific Research Publishing Inc. This work is licensed under the Creative Commons Attribution International License (CC BY 4.0).

http://creativecommons.org/licenses/by/4.0/

c) (i) Open Access

\begin{abstract}
Over the last decade, with the emergence of cyberbullying (CB) in the education arena, teachers at all stages of the education system have confronted new challenges. Few studies have looked into the factors that affect the coping. This study examines teaching background factors and personal-psychological factors that may affect teachers coping with CB. Six hundred forty-four teachers (81.5\% female) completed self-reported questionnaires referring to $\mathrm{CB}$ coping, empathy level, communication with students level and teachers' self-efficacy. Results have revealed that overall, teachers were reported on moderate levels of coping with $\mathrm{CB}$. Pearson correlations indicated that CB coping is correlated positively with high levels of empathy, communication with students, and teachers' self-efficacy. A multiple regression analysis for predicting effective coping with CB exposed a significant model showing that seniority, empathy, and high levels of teachers' communication with students may predict teachers' coping with $\mathrm{CB}$, whereas age and gender do not. Furthermore, the results of a mediation model have revealed that empathy and teacher self-efficacy mediate the influence of teacher communication with students on $\mathrm{CB}$ coping. However, we found no direct effect of teacher communication with students on $\mathrm{CB}$ coping. The results have significant implications for teachers' education programs.
\end{abstract}

\section{Keywords}

Cyberbullying, Teachers Coping, Teachers Education Programs

\section{Introduction}

Cyberbullying in the teaching-learning context

Over the last decade, teachers have confronted new challenges in coping with 
cyberbullying (CB) acts (Eden, Heiman, \& Olenik-Shemesh, 2013). Dealing with $\mathrm{CB}$ raises new challenges for the education staff as a result of the unique characteristics of the phenomenon. $\mathrm{CB}$, a threat without a face, is defined as an intentional act via electronic media to harm, embarrass, and/or humiliate another person (Smith et al., 2008; Bilik, 2013). It is characterized by an over-time repetitive, anonymous, and massive audience, easy access, online disinhibition effects, difficulty in exposure, revealing and reporting and absence of non-verbal messages. CB has a direct impact on the learning and teaching dynamics, as well on student emotional and social functioning in class and in school (Iranzoa et al., 2019; Olenik-Shemesh, Heiman, \& Eden, 2012). Studies in the past decade have found that $\mathrm{CB}$ has negative consequences on the mental health of the victim as well as on the perpetrator and the bystanders, at school and in the students' daily lives anywhere (Huang \& Chou, 2010; González-Cabrera, León-Mejía, \& Beranuy, 2018).

In addition to its social-emotional consequences, $\mathrm{CB}$ also affects the learning process (Shariff \& Hoff, 2007). Emotions arising as a result of the hurt, such as fear, frustration, anxiety, and mood swings, divert the student's attention from learning and academic tasks and affect the class and school climate, thereby diminishing learning opportunities (Shariff \& Hoff, 2007; Ybarra, Diener-West, \& Leaf, 2007), and may lead to a decline in motivation, scores, and concentration alongside a rise in absenteeism (Beale \& Hall, 2007; Li, 2008).

The teaching-learning environment plays a key role in coping with CB; thus, teachers are at the forefront of coping with student aggression, including in the form of CB (Spears et al., 2009). They are the ones who confront the students and frequently encounter any acts of bullying. Studies show most teachers are familiar with the effects of $\mathrm{CB}$ on students, but they do not think it is a school problem (Li, 2007). They are not confident in their ability to identify and cope with it. They often feel unable to cope, but are pressured by the principal and parent to report difficulties in ensuring a safe learning environment for students (Eden, Heiman, \& Olenik-Shemesh, 2013; Siu, 2004).

The teacher's work consists of managing the learning environment surrounding the social environment that is intertwined with various levels of dynamic relationships. For their students to achieve academically, the teachers must support them scholastically, emotionally, and socially, and thus should be able to cope effectively with $\mathrm{CB}$, because the $\mathrm{CB}$ phenomenon plays a significant role in the lives of students of all ages today. Schools (Giménez-Gualdo \& Carrión del Campo, 2018), but only a few studies have examined in depth the teachers' perspectives, perceptions, and awareness of CB (Huang \& Chou, 2013).

Generally, teachers are required to cope with $\mathrm{CB}$ at three main levels: Assist students who are $\mathrm{CB}$ victims and cope with the impact of the $\mathrm{CB}$ acts on students' function among: scholastic, social and emotional; handle the aggressive behavior of the perpetrators: Individual and groups and also in the personal level: as being targets of CB by students. 


\section{Teachers' coping strategies and interventions in $\mathrm{CB}$ among students}

Giménez-Gualdo and Carrión del Campo (2018) find the most common strategies for teachers coping with $\mathrm{CB}$ and helping its victims are asking for help from their work colleagues, involving the parents and talking to the students. Many teachers report to the school administration or talk with the cyber-victim and the cyber-perpetrator. Another means of coping is to involve the school counselor and law enforcement figures. Teachers also report difficulty in activating sanctions against the perpetrators given the lack of appropriate resources for handling the school's social environment and the lack of attention paid to those affected by $\mathrm{CB}$. The authors find elementary school teachers intervene more in the handling of $\mathrm{CB}$ than middle school teachers. The study also revealed that $\mathrm{CB}$ victims tend to report to family members more than to their teachers, and that students do not perceive their teachers as a resource that can help them resolve conflicts regarding acts of $\mathrm{CB}$; thus, they almost have never approach them for help. Similarly, students do not turn to the school counselors for help, despite the importance of the counselors in assessing the issues of prevention and intervention in online bullying and violence, and they are not confident in the teachers' and counselors' ability to solve CB problems. Giménez-Gualdo \& Carrión del Campo (2018) highlight the importance of training teachers and developing models of how to cope with $\mathrm{CB}$ and of coordinating the efforts of the students and the teachers.

Few studies have explored the personal and psychological factors that may affect teachers' coping with $\mathrm{CB}$, but several have detected the following factors as being linked to teachers' awareness of CB:

- Technological exposure. Teachers who use the internet more than 15 hours a week are more aware of CB than those who use it fewer hours per week, as are teachers of technology subjects (IT) (Sezer et al., 2015; Popovic-Citic et al., 2011).

- Teachers victimization. Teachers who have been personally affected by CB are approached more often by students and are more aware and knowledgeable of the phenomenon (Eden, Heiman, \& Olenik-Shemesh, 2013).

- Differences between teacher stages of education, types of schools, and types of teachers. Elementary school teachers express greater concern and greater responsibility than teachers of middle and high school students. Elementary, middle school, homeroom teachers, and special education teachers are more concerned about and aware of CB and its effects than high school and subject-matter teachers, as well as teachers in mainstream education classes (Eden, Heiman, \& Olenik-Shemesh, 2013; Li, 2008).

In light of the potentially key role teachers and other educational staff play in coping with $\mathrm{CB}$, and in light of the findings mentioned above, room remains for in-depth exploration to understand the factors affecting teachers' intervention in and coping with $\mathrm{CB}$ among their students. Although a few studies have investigated teachers' awareness and coping with $\mathrm{CB}$, almost no study have looked into 
the factors that affect their coping.

\section{Factors affecting teachers' intervention strategies}

This study examines teaching-background factors and personal-psychological factors that may affect teachers coping with CB. More specifically, it examines whether and how the teachers' personal and teaching-background variables (gender, age, teaching seniority) alongside their personal-psychological variables (level of empathy, level of teacher communication with students, and teachers' self-efficacy) affect teachers' coping with CB.

Detecting such factors may help in developing teachers' education programs for coping with $\mathrm{CB}$, as well as in improving existing programs through more precise planning.

Gender, age, and seniority in teaching are background variables that have emerged from the literature as supporting teachers' coping with violence, bullying, and various stress encounters in the classroom (Yorulmaz \& Altınkurt, 2018; Prasad, Vaidya, \& Kumar, 2016). However, these key variables have not been examined as possible factors that affect teachers' ability to cope with CB.

Gender difference. Studies investigating gender as it relates to teachers' awareness of CB have yielded contradictory findings. Some studies have found no gender differences (Huang \& Chou, 2013); others have found women teachers have a higher chance of working with the perpetrator and soliciting help from others when needed (Bauman, Rigby, \& Hoppa, 2008; Giménez-Gualdo \& Carrión del Campo, 2018; Eden, Heiman, \& Olenik-Shemsh, 2013). Huang and Chou (2013) claim that knowledge and skills regarding technology are more linked than gender to teachers' awareness.

Teaching age and seniority. Yoon et al. (2011) found that younger and less senior teachers are more aware of and concerned with the phenomenon than older and more senior teachers (26 years and older, and with 10 - 16 years of seniority).

Teachers empathy. Empathy is related to one's ability to feel and share another person's emotions, and includes a wide range of emotional states, including experiencing emotions that match another person's emotions, caring for other people, and sensitivity to other peoples' thoughts and feelings. It refers also to a person's awareness of the immediate sensitivity of the other and the ability to identify and understand other people's feelings and their private world, without losing oneself in it (Ang \& Goh, 2010). Empathy requires an ability to be attentive to others' feelings, thoughts, and behaviors (Kaniel, 2013).

Teachers' management of emotions in class is considered to be at the core of their job (Kelchtermans, 2011). Studies show that teachers' emotions are as important as their pedagogical-didactic abilities. In education processes, empathy refers to the ability of educators to identify and understand their students' or mentees' distress, suffering, and point of view. Teachers' empathy may improve interpersonal communication in the class, help resolve conflicts, and reduce bullying (Kaniel, 2013). Empathic relation between teachers and students is a prerequisite to enable students to trust and learn from their teachers (Oplatka, 
2018). The sense of safety such relationships provide enables students to use their teachers as a resource for different types of coping (Howes \& Ritchie, 2002; Pianta, Hamre, \& Stuhlman, 2003). Howie and Ritchie (2013) found that students in high-quality community programs and children who have a close relationship with their teacher reach higher achievements in language and in social-skill acquisition. Oplatka (2018) reports that students develop a sense of self-efficacy, high self-confidence, and a positive self-image thanks to close relationships with and receiving empathy from their teaching staff. Research has also found that empathic teachers enable learning that is meaningful to the students (Lampert, 2008; Beck, 2012). Additionally, identifying the spectrum of bullying behaviors alongside practicing empathy are the first steps to developing the ability to cope with any kind of bullying (Craig, Henderson, \& Murphy, 2000).

Cooper (2011) identified three levels of teachers' empathy toward students: basic, deep, and functional. Basic empathy refers to the positive social cues that most people use in daily conversations and relations, characterized by openness, attentive listening, expressing interest, positive attitude, expressing enthusiasm, and communication that takes place via facial expression, body gestures, body language, and tone of speech, and that serve as a platform for deeper empathic relations. Deep empathy refers to a deeper and broader understanding of the students, suited to closer and longer relationships. Together with basic empathy, it represents broad, rich, empathic relationships in the educational framework that include understanding students' feelings and being able to verbalize such understanding, taking responsibility for one's actions, evaluating relationships, developing positive feelings and interactions, and personal, social, and moral versatility and flexibility. The interactions are more personal and enjoyable, thus empowering the learning process and the motivation on both sides-teachers and students. Functional empathy refers to the ability to adapt oneself to the needs of the class, as a unit, usually limited to a specific context (Cooper, 2011).

Teacher-student communication. Another main variable that may affect teachers' coping with $\mathrm{CB}$, teacher-student communication refers to the interpersonal connection with and communication between the teacher and the student that determines - to a great extent-whether the student experiences a rapprochement, understanding, and change, or rather experiences frustration, failure, and regression. These experiences can enhance or destroy the opportunity for effective learning and trust relations with teachers in particular and with adults in general (Aharonson \& Bar Shalom, 2010). Thus, in addition to adaptive teaching, teachers need to be capable of meaningful personal contact with others (Oplatka, 2018). An encounter with a teacher that provides a safe foundation for bonding and good teacher-student communication might create a new opportunity that will become part of the child's social-emotional repertoire, which affects social-emotional adjustment as well as learning (Al-Yagon \& Mikulincer, 2006). Oplatka (2018) found a correlation between students' assessment of their teachers as a safe foundation and the perception of their emotional and social 
adaptability. The more highly the students valued their teachers as a safe foundation, the more they reported secure feelings regarding the world around them and seeing themselves as less isolated.

In class, good teacher-student communication encourages dialogue, expresses sensitivity toward students' needs, provides a safe learning environment, encourages private conversations with students, monitors trouble-making students during recess, or initiates individual chats with students at risk in their free time (Oplatka, 2018). When teachers have good communication with their students, they can cope more effectively with incidents of CB, both in the likelihood of being approached by the students and in providing them with appropriate help.

Teachers's sense of self-efficacy. Another important variable in this context is the sense of self-efficacy. A high sense of self-efficacy means believing in one's ability to attain a desired outcome through intentional acts (Bandura, 1993). Experiences of success and failure and the interpretations that the person and the environment give them are the main source of the sense of self-efficacy (Kaniel, 2013). People with similar talents might reach different outcomes because of a different sense of self-efficacy (Bandura, 1993; Zimmerman, Bandura, \& Martinez, 1992). Self-efficacy touches upon a person's evaluation of his or her ability to successfully organize and perform a behavior or set of behaviors that will lead to a desired outcome (Bandura, 1982; Friedman \& Kass, 2000). The concept distinguishes between existing skills and the belief in ability and outcomes. The sense of self-efficacy affects a person who is considering whether to perform any given behavior, how much effort to invest in it, how one feels about it, and whether one thinks he or she will perform it successfully (Friedman \& Kass, 2000). According to Bandura (1982), factors such as anxiety, self-perception, and efficiency are seen as affecting behavior, but they are actually the outcome of the sense of self-efficacy. This sense mediates the influence of factors such as gender and prior experiences.

Among teachers, the sense of self-efficacy refers to the extent to which a teacher believes in his or her ability to affect student performance and reach a desired result, the belief in the ability to fulfill the conventional task of teaching (humane, considerate, and flexible teaching; teaching that is interesting and beneficial; control of the students and their behavior; ability to influence important decisions at school and to maintain his or her status and image as a leader in the eyes of the students (Friedman \& Kass, 2000). This definition is informed by the teacher's two main roles at school: 1) teaching and managing class, and 2) membership and partnership in the school as an organization. In the first role, the task aspect (teaching) differs from the human aspect (relations with the students).

The teacher's sense of self-efficacy consists of three elements: teaching, participating in the organization, and managing relationships. Teacher self-efficacy in the task of teaching has three components: 1) humaneness, consideration, and flexibility_creating positive changes in students' lives, matching the difficulty 
level of the studies and the teaching to the level of the students, influencing their values and morals, identifying and resolving problems among students, being flexible in teaching; 2) interesting and beneficial teaching-connecting the study material to daily life, activating students' creativity, practicing pedagogy that is beneficial to the students, engaging in interesting and motivating teaching; 3) control of the students and their behavior-managing students' response to teacher demands, being able to easily control and overcome student interruptions.

Teacher self-efficacy in the realm of the organization is the extent to which the teacher feels capable of influencing important decisions at the school. This feeling may be expressed in active partnership in making these decisions and in formulating school policy, and a high level of assertiveness vis-à-vis the principal or the school administration. Relationships in the realm of teacher self-efficacy are defined as the informal aspect (interpersonal relationships) of the connection between teacher and student, maintaining the status of the teacher in the eyes of the student despite displays of closeness and friendship, the ability (or inability) to show the student warmth and empathy, and, in general, the image of the teacher as a leader in the eyes of the student (Friedman \& Kass, 2000). A high sense of self-efficacy leads to feeling less stress and seeing the situations they encounter as less threatening (Bandura, 1986), and thus may help teachers cope more effectively with stress encounters that include incidents of $\mathrm{CB}$. Ashton, Webb, and Doda (1983) found a positive correlation between teacher self-efficacy and the ability to effectively confront and handle student-discipline problems.

\section{The present study}

As mentioned above almost no study has explored factors that may affect teachers' coping with cyberbullying CB. The main goal of the current study was to investigate whether and how the teachers' background variables (gender, age, and teaching seniority), alongside specific personal-psychological variables (level of empathy, level of teacher communication with students, and teachers' sense of self-efficacy), affect teachers' coping with $\mathrm{CB}$.

More specifically, we hypothesized that age and seniority in teaching, as well as high levels of empathy, teacher communication with students, and teachers' self-efficacy, are positively correlated with teachers' effective coping with $\mathrm{CB}$. female teachers can cope more effectively than men, that age, gender (male/female), seniority, empathy, and self-efficacy predict coping, and that the influence of teachers' communication on $\mathrm{CB}$ coping is mediated by empathy and teachers' self-efficacy.

\section{Methodology}

\section{Participants and Procedure}

The study included 644 teachers, randomly sampled from urban middle schools in the center of the country. The sample addressed municipal schools and included both homeroom and professional teachers. The majority of the 
participants were female (525 [81.5\%], Mage $=43.95, S D$ age $=11.93)$. Seniority in teaching ranged from 0 to 45 years $(M=16.17, S D=11.27)$.

Participants recruited using an online panel survey completed individually the questionnaire online. They were informed about the aims of the study, and that their participation was voluntary and would remain anonymous. They were also assured they could withdraw from the study at any time. The researchers' contact details were included for participants' enquiries regarding the study. Data were analyzed using IBM SPSS (Version 25.0) and R-Studio (Version 3.5.1).

\section{Measures}

Cyberbullying perception and coping with cyberbullying scale (Li, 2008). This Scale present 26 statements regarding teachers awareness and coping with $\mathrm{CB}$ using the 1 - 5 scale on a 5 -point Likert scale $(1=$ slightly, $5=$ very much $)$, where higher scores represent a higher level of CB coping. The Cronbach's alpha of the scale is .88 and in the cuurebt study .86 .

Empathy Questionnaire (Davis, 1983). The questionnaire includes 28 statements, which describe behaviors, on a from 1 to 5 likert scale, regarding the extent to which the statements describe the participant. The statements are grouped into four categories: Perception of the other person, fantasy, empathic concern and personal concern. Higher scores represent a higher level of empathy. According to Davis (1983) these categories can be used as single scales. In the present study, we used "empathic concern" and the "perception of the other person", thus, it included 14 items. The Cronbach's alpha is .67.

Teachers Communication with students scale. Based on the Parent-student communication scale (Barnes \& Olson, 1985), the Communication Techers-Students Scale present 20 statements, aiming to examine the teacher-student communication according to the teacher's perception, relating to the degree of openness between teacher and student and the degree of problems and difficulties in this communication. Using the 1 - 5 scale on a 5 -point Likert scale $(1=$ strongly disagree 5 = strongly agree), the scale is designed to measure the communication level in class, whereas higher score represents a higher level of communication. Cronbach's alpha in general is .79- .89 and in the current study -.79 .

Teachers' self-efficacy scale. (Friedman \& Kass, 2002), present 29 statements, using a 6-point Likert scale $(1=$ never. $6=$ always $)$. The scale measures teacher's sense self-efficacy as a teacher (in relation to the teaching tasks, to the organization and to teachers relationship with their students). Higher scores represent a higher level of positive self-efficacy as teachers. Cronbach's alpha is .89.

\section{Results}

\section{Descriptive Statistics and Correlations}

Overall, the participants reported moderate levels of CB coping $(M=3.96, S D$ $=0.49)$, moderate levels of communication $(M=3.66, S D=.39)$, high levels of empathy $(M=3.11, S D=.35)$, and high levels of teachers' self-efficacy $(M=$ $4.29, S D=.53)$. Means, standard deviations, and Cronbach's alphas are shown in Table 1. 
Table 1. Means, standard deviations, Cronbach's alphas, and correlations.

\begin{tabular}{lccccccccc}
\hline \multicolumn{1}{c}{ Variable } & $M$ & $S D$ & Alpha & 1 & 2 & 3 & 4 & 5 & 6 \\
\hline 1. Gender & 1.82 & 0.39 & & & & & & & \\
2. Age & 43.88 & 11.95 & & .01 & & & & & \\
3. Seniority & 16.17 & 11.53 & & .01 & $.84^{* *}$ & & & & \\
4. Cyberbullying coping & 3.96 & 0.49 & .86 & .05 & .01 & -.02 & & & \\
5. Empathy & 3.11 & 0.35 & .67 & $.18^{* *}$ & $.10^{* *}$ & $.12^{* *}$ & $.28^{* *}$ & & \\
6. Communication & 3.66 & 0.39 & .75 & $.12^{* *}$ & .02 & $.09^{*}$ & $.17^{* *}$ & $.32^{* *}$ & \\
7. Teachers' self-efficacy & 4.29 & 0.53 & .89 & .02 & $.22^{* *}$ & $.29^{* *}$ & $.26^{* *}$ & $.36^{* *}$ & $.49^{* *}$ \\
\hline
\end{tabular}

Note. Gender, 1 = male, $2=$ female. $M$ and $S D$ are used to represent mean and standard deviation, respectively. Alpha represents Cronbach's alphas. ${ }^{*}$ indicates $p<.05 .{ }^{*}$ indicates $p<.01$.

Pearson correlations were conducted between the examined variables. As Table 1 shows that gender (males/female) is correlated positively with empathy ( $r$ $=.18, p<.01)$ as well as with communication with students $(r=.12, p<.01)$, meaning that female teachers report higher levels of empathy and communication than male teachers. Also, age is correlated positively with seniority $(r=.84$, $p<.01)$ and empathy $(r=.10, p<.01)$, indicating that older teachers, who are more experienced in the education system, present a higher level of empathy than younger teachers. Moreover, seniority is correlated with communication $(r$ $=.09, p<.05)$, empathy $(r=.12, p<.01)$, and teachers' self-efficacy $(r=.29, p$ $<.01$ ), which shows that the more experienced teachers have in the education system, the higher their levels of communication, empathy, and self-efficacy as teachers.

As hypothesized Teachers coping with $\mathrm{CB}$ was positively correlated with empathy, communication with students and self-efficacy but no significant correlations were found with gender age and seniority.

\section{Regression Analysis}

A regression analysis was conducted for predicted $\mathrm{CB}$ coping. The following independent variables were entered in one step: age, gender (male/female), seniority, empathy, teachers' self-efficacy, communication, and teachers' self-efficacy $\mathrm{X}$ communication interaction.

As shown in Table 2, the regression model was significant, which explains $13 \%$ of the variance in $\mathrm{CB}$ coping: $F(7,635)=13.11, p<.001, R^{2}=13$. Of the independent variables, seniority shows a significant main effect $(\beta=-.01, \mathrm{t}(643)=$ $-2.26, p<.05)$, as do empathy $(\beta=.29, \mathrm{t}(643)=4.97, p<.001)$, communication with students $(\beta=.74, \mathrm{t}(643)=2.13, p<.05)$, and teachers' self-efficacy $(\beta=.80$, $\mathrm{t}(643)=2.72, p<.01)$, whereas age and gender do not. In addition, the interaction between teachers' self-efficacy and communication shows a significant main effect $(\beta=-.17, \mathrm{t}(643)=-2.11, p<.05)$.

Simple slops analysis shows teachers' self-efficacy was significantly related to $\mathrm{CB}$ coping when communication was one standard deviation below the mean (b $=3.28, \mathrm{t}(644)=4.80, p<.001)$, at the mean $(\mathrm{b}=3.66, \mathrm{t}(644)=4.53, p<.001)$, 
Table 2. Regression results using CB coping as the criterion.

\begin{tabular}{ccccc}
\hline Predictor & $b$ & SEB & $\beta$ & $t$ value \\
\hline (Intercept) & -.42 & 1.25 & & -.43 \\
Age & -1.00 & .01 & -.01 & .96 \\
Gender & .20 & .05 & .01 & .07 \\
Seniority & -1.00 & .01 & -.01 & $-2.26^{\star}$ \\
Empathy & 4.83 & .06 & .29 & $4.97^{* * *}$ \\
Communication & 2.11 & .35 & .74 & $2.13^{*}$ \\
Teachers' Self-efficacy & 2.76 & .29 & .80 & $2.72^{* *}$ \\
Teachers' Self-efficacy X Communication & -2.13 & .08 & -.17 & $-2.11^{\star}$ \\
\hline
\end{tabular}

Note. Gender, $1=$ male, $2=$ female. $R=.36, R^{2}=.13$, Adj. $R^{2}=.12, F(7,635)=13.11, p<.001 .{ }^{*}$ indicates $p$ $<.05 .{ }^{* *}$ indicates $p<.01 .{ }^{* * *}$ indicates $p<.001$.

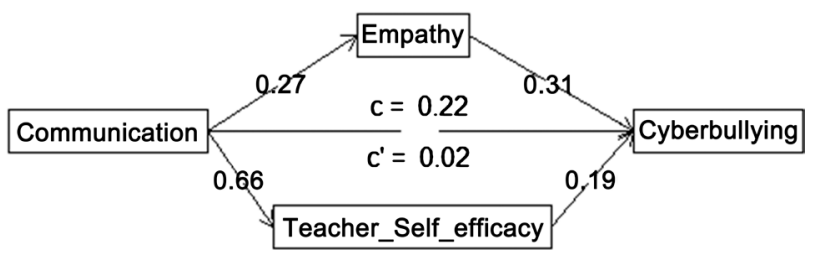

Figure 1. Indirect (mediation) model.

and one standard deviation above the mean $(\mathrm{b}=4.05, \mathrm{t}(644)=2.48, p<.01)$.

\section{Mediation Model}

To examine whether teachers' communication with students may affect CB coping via empathy and teachers' self-efficacy, we conducted a mediation model linking communication to $\mathrm{CB}$ through empathy and teachers' self-efficacy (see Figure 1). To control for age, gender, and seniority, we entered those variables as covariance in the model. The results show a significant positive indirect effect of the communication of $\mathrm{CB}$ coping through empathy $(b=.08,[.05 ; .12], p$ $<.001)$. In addition, we found a significant positive indirect effect of the communication of $\mathrm{CB}$ coping via teachers' self-efficacy $(b=.12$, $[.07 ; .18], p<.001)$.

The results indicate empathy and teachers' self-efficacy mediates the influence of teachers' communication on $\mathrm{CB}$ coping. However, we found no direct effect of communication on $\mathrm{CB}$ coping $(b=.02, \mathrm{t}(639)=5.30, p=.76)$.

\section{Discussion and Implications}

The current study presents an in-depth examination of personal, teachingbackground variables and significant psychological variables that may affect teachers coping with $\mathrm{CB}$. The findings reveal CB coping may be predicted by seniority of teaching, high levels of empathy, good communication with students and teachers' self-efficacy, but not by age and not by gender. The interaction between teachers' self-efficacy and communication may also predict effective coping. It was also found that association between teachers' communication with students and CB coping is mediated by empathy and teachers' self-efficacy. 
These findings have implications at both theoretical and practical levels. At the theoretical level, the research findings add considerable knowledge regarding teachers coping with violence in general and with online violence in particular, by identifying personal factors that significantly affect the coping process. On a practical level, whereas other findings have pointed to a few main elements involved in the successful training of educational staff, including emphasizing the importance of encouraging the reporting of cases of $\mathrm{CB}$, keeping teachers updated on new technologies and their use by students, and creating an atmosphere in which students feel safe to report CB (Englander \& Muldowney, 2007; $\mathrm{Li}, 2008$ ), the findings of the current study indicate specific factors that should be implemented and emphasized in teachers' education training programs relating to coping with $\mathrm{CB}$, an issue that has become central and challenging in schools. It is recommended that such programs will include enhancing levels of teachers' empathy, their sense of self-efficacy and their communication with students. Continued research on this topic is needed in order to explore various ways to develop effective communication and authentic discourse between teachers and students. On the other hand, the findings also indicated that there is no need to address age and gender when developing such an intervention program.

Other studies have found that when encouraging students to report $\mathrm{CB}$, programs should meaningfully involve a parent or guardian (Snakenborg et al., 2011), raise awareness of educational staff to the phenomenon of CB and its implications, teach educators how to recognize and cope with CB, and increase supervision of students using technology for learning purposes (Patchin \& Hinduja, 2010).

Researchers claim that despite some increase in awareness of $\mathrm{CB}$, providing teachers with more specific programs for coping with $\mathrm{CB}$ is important in order to assist them with prevention and classroom intervention (Giménez-Gualdo \& Carrión del Campo, 2018; Englander \& Muldowney, 2007). Whereas most programs relate to identifying $\mathrm{CB}$, its effects on students, and acquisition of tools for knowing how to manage $\mathrm{CB}$ incidents, many teachers report that their teacher training program did not properly prepare them for coping (Styron et al., 2016). Programs that will include components such as school and class atmosphere, social activities, cultivation of classroom relationships, and personal teacher-student relationships are necessary (Giménez-Gualdo \& Carrión del Campo, 2018). The findings of the current study suggest specific variables that should be included in such programs. These variables relate to personal factors of the teachers that may increase their ability to cope with CB episodes and may fill the gaps in the existing programs. More specifically, the findings indicate training and education programs that include developing teachers' empathy, improving communication with students, and raising self-efficacy may contribute significantly to teachers' coping.

Teacher-related personal factors seem to play a significant role in tackling CB incidents that have a negative impact on the school climate, according to the re- 
port by the US National Center for Education Statistics (NCES, 2011) on predicted crucial factors in teacher attrition, especially within the first year of teaching. Teachers report a high percentage of attrition as a result of working under a negative school climate and inappropriate student behavior, such as CB (Styron et al., 2016). Thus, more specific, personal, targeted programs may prevent teacher burnout and attrition.

Finally, while planning teachers' education program for coping with $\mathrm{CB}$, considering the educational parent-student-teacher triangle is vital. The development of sensitivity and empathy binds these partners and brings together their emotional, familial, and personal experiences. Parent-teacher relationships may be conflictual and are one of the greatest challenges educators currently face, but such relationships are important in coping with violence and bullying (Oplatka, 2018).

\section{Limitations and future directions}

Some limitations should be noted. Regarding gender, most of the participants (almost 82\%) were female; thus, future studies regarding teachers coping with $\mathrm{CB}$ should include more male teachers in order to get a more complete picture. However, most teachers are women. The measures in this study are all self-reported questionnaires, and integrating qualitative analyses of teacher interviews and focus groups would be beneficial and add to the validity of the study. Furthermore, to get a broader picture, we need to investigate more relevant psychological, emotional, and social personal factors that affect teachers' coping. More generally, in light of the increased prevalence of $\mathrm{CB}$ among students and the increase in technology usage, more studies need to address teacher preparation in coping with these online behaviors.

\section{Conflicts of Interest}

The authors declare no conflicts of interest regarding the publication of this paper.

\section{References}

Aharonson, H., \& Bar-Shalom, Y. (2010). The Implementation of the Self-Approach and the Attribution Approach to Decoding Emotional Situations (Personal and Interpersonal) in the Teacher-Student Relationship. Yozma, 92-142. (Hebrew)

Al-Yagon, M., \& Mikulincer, M. (2006). Children's Appraisal of Teacher as a Secure Base and Their Socio-Emotional and Academic Adjustment in Middle Childhood. Research in Education, 75, 1-18. https://doi.org/10.7227/RIE.75.1

Ang, R. P., \& Goh, D. H. (2010). Cyberbullying among Adolescents: The Role of Affective and cognitive Empathy and Gender. Child Psychiatry \& Human Development, 41, 387-397. https://doi.org/10.1007/s10578-010-0176-3

Ashton, P. A., Webb, R., \& Doda, N. (1983). A Study of Teacher's Sense of Efficacy. Final Report to the National Institute of Education, Executive Summary. Gainesville, FL: Florida University.

Bandura, A. (1982). Self Efficacy Mechanism in Human Agency. American Psychologist, 
37, 122-147. https://doi.org/10.1037/0003-066X.37.2.122

Bandura, A. (1986). Social Foundation of Thought and Action: A Social Cognitive Theory. Englewood Cliffs, NJ: Prentice-Hall. https://doi.org/10.5465/amr.1987.4306538

Bandura, A. (1993). Perceived Self-Efficacy in Cognitive Development \& Functioning. Educational Psychologist, 28, 117-148. https://doi.org/10.1207/s15326985ep2802_3

Barnes, H. L., \& Olson, D. H. (1985). Parent-Adolescent Communication and the Circumplex Model. Child Development, 56, 438-447. https://doi.org/10.1111/j.1467-8624.1985.tb00118.x

Bauman, S., Rigby, K., \& Hoppa, K. (2008). US Teachers' and School Counsellors' Strategies for Handling School Bullying Incidents. Educational Psychology, 28, 837-856. https://doi.org/10.1080/01443410802379085

Beale, A., \& Hall, K. R. (2007). Cyber-Bullying: What School Administrators and Parents Can Do. Clearing House, 81, 8-12. https://doi.org/10.3200/TCHS.81.1.8-12

Beck, S. (2012). Contradictory Logics in Teacher Training. In R. Klavir, \& L. Kozminsky (Eds.), Constructing Professional Identity: Training Processes and Professional Development of Teachers in Israel. Tel Aviv: Mofet Institute Press (Hebrew). http://sagepub.co.uk/journalspermissions.nav

Bilic, V. (2013). Violence among Peers in the Real and Virtual World. Pediatrics Today, 9, 78-90. https://doi.org/10.5457/p2005-114.65

Cooper, B. (2011). Empathy in Education: Engagement, Values \& Achievement. London: Continuum International Publishing Group.

Craig, W., Henderson, K., \& Murphy, J. (2000). Prospective Teachers' Attitudes toward Bullying Interventions. School Psychology International, 21, 475-487. https://doi.org/10.1177/0143034300211001

Davis, M. (1983). Measuring Individual Differences in Empathy: Evidence for a Multidimensional Approach. Journal of Personality nd Social Psychology, 44, 113-126. https://doi.org/10.1037//0022-3514.44.1.113

Eden, S., Heiman, T., \& Olenik-Shemesh, D. (2013). Teachers' Perceptions, Beliefs and Concerns about Cyber-Bullying. British Journal of Educational Technology, 44, 1036-1052. https://doi.org/10.1111/j.1467-8535.2012.01363.x

Englander, E., \& Muldowney, A. M., (2007). Just Turn the Darn Thing off: Understanding Cyber-Bullying. Proceedings of the National Conference on Safe Schools and Communications, USA.

http://vc.brdgew.edu/cgi/viewcontent.cgi/viewcontent.cgi?article=1011\&content=marc _pubs

Friedman, Y. \& Kass, E. (2002) Teacher Self-Efficacy: Concept and Measurement. Jerusalem: Henrietta Szold Institute Press. (In Hebrew)

Giménez-Gualdo, A., \& Carrión del Campo, J. (2018). El Profesorado Ante el Cyberbullying: Necesidades Formativas, Capacidad de Actuación y Estrategias de Afrontamiento. Bordon Journal of Education, 70, 43-56. https://doi.org/10.13042/Bordon.2018.52067

González-Cabrera, L., León-Mejía, A., \& Beranuy, M. (2018). Relationship between Cyberbullying and Health-Related Quality of Life in a Sample of Children and Adolescents. Quality of Life Research, 27, 2609-2618.

https://doi.org/10.1007/s11136-018-1901-9

Howes, C., \& Ritchie, S. (2002). A Matter of Trust: Connecting Teachers and Learners in the Early Childhood Classroom. New York: Teachers College Press.

Howie, P., \& Bagnall, R. (2013). A Critique of the Deep and Surface Approaches to 
Learning Model. Teaching in Higher Education, 18, 389-400.

https://doi.org/10.1080/13562517.2012.733689

Huang, Y. Y., \& Chou, C. (2010). An Analysis of Multiple Factors of Cyberbullying among Junior High School Students in Taiwan. Computer and Human Behavior, 26, 1581-1590. https://doi.org/10.1016/j.chb.2010.06.005

Huang, Y. Y., \& Chou, C. (2013). Revisiting Cyber-Bullying: Perspectives from Taiwanese Teachers. Computers \& Education, 63, 227-239. https://doi.org/10.1016/j.compedu.2012.11.023

Iranzoa, B., Buelgab, S., Cavab, M., \& Ortega-Barónc, J. (2019). Cyberbullying, Psychosocial Adjustment, and Suicidal Ideation in Adolescence. Psychosocial Intervention, 28, 75-81. https://doi.org/10.5093/pi2019a5

Kaniel, S. (2013). Empathy in Education. Education with Love. Tel Aviv: MOFET Institute Press. (Hebrew).

Kelchtermans, G. (2011). Vulnerability in Teaching: The Moral and Political Understanding of Teacher's Work: Professional Learning and Development in Schools and Higher Education (pp. 65-82). Dordrecht: Springer. https://doi.org/10.1007/978-94-007-0545-6_5

Lampert, H. (2008). Empathic Education as a Critique of Neo-Capitalism. Tel Aviv: Resling (Hebrew).

Li, Q. (2007). Bullying in the New Playground: Research into Cyber-Bullying and Cybervictimization. Australasian Journal of Educational Technology, 23, 435-454.

https://doi.org/10.14742/ajet.1245

Li, Q. (2008) Cyber-Bullying in Schools: An Examination of Pre-Service Teachers' Perception. Canadian Journal of Learning and Technology, 34, 75-90. https://doi.org/10.21432/T2DK5G

National Center for Educational Statistics (NCES) (2011). Beginning Teacher Attrition and Mobility: Results from the First through Third Waves of the 2007-08 Beginning Teacher Longitudinal Study.

Olenik-Shemesh, D., Heiman, T., \& Eden, S. (2012). Cyberbullying Victimization in Adolescence: Relationships with Loneliness and Depressive Mood. Emotional and Behavioural Difficulties, 17, 361-374. https://doi.org/10.1080/13632752.2012.704227

Oplatka, I. (2018). Emotions in Teaching and School Management. Anthology of Articles. Tel-Aviv: MOFET Institute Press (Hebrew).

Patchin, J. W., \& Hinduja, S. (2010). Bullying, Cyberbullying, and Suicide. Archives of Suicide Research, 14, 206-221. https://doi.org/10.1080/13811118.2010.494133

Pianta, R. C., Hamre, B., \& Stuhlman, M. (2003). Relationships between Teachers and Children. In W. Reynolds, \& G. Miller (Eds.), Comprehensive Handbook of Psychology: Educational Psychology (Vol. 7, pp. 199-234). New York: Wiley. https://doi.org/10.1002/0471264385.wei0710

Popovic-Citic, B., Djuric, S., \& Cvetkovic, V. (2011). The Prevalence of Cyber-Bullying among Adolescents: A Case Study of Middle Schools in Serbia. School Psychology International, 32, 412-424. https://doi.org/10.1177/0143034311401700

Prasad, K. D. V., Vaidya, R., \& Kumar, V. A. (2016). Teacher's Performance as a Function of Occupational Stress and Coping with Reference to CBSE Affiliated School Teachers in and around Hyderabad: A Multinomial Regression Approach. Psychology, 7, 1700-1718. https://doi.org/10.4236/psych.2016.713160

Sezer, B., Yilmaz, R., Gizeman, F., \& Yilmaz, K. (2015). Cyber-Bullying and Teachers Awareness: The Case of Turkey. Internet Research, 25, 674-687. 
https://doi.org/10.1108/IntR-01-2014-0023

Shariff, S., \& Hoff, D. L. (2007). Cyber-Bullying: Clarifying Legal Boundaries for School Supervision in Cyber-Space. International Journal of Cyber Criminology, 1, 76-117.

Siu, C. (2004). Pre-Service Teachers' Attitudes about School Bullying: A New Perspective (pp. 51-67). Calgary: University of Calgary.

Smith, P. K., Mahdavi, J., Carvalho, M. S., Fisher, S., Russell, S., \& Tippett, N. (2008). Cyber-Bullying: Its Nature and Impact on Secondary School Pupils. Journal of Child Psychology and Psychiatry, 49, 376-385. https://doi.org/10.1111/j.1469-7610.2007.01846.x

Snakenborg, J., Van Acker, R., \& Gable, R. A. (2011). Cyber-Bullying: Prevention and Intervention to Protect Our Children and Youth. Preventing School Failure: Alternative Education for Children \& Youth, 55, 88-95. https://doi.org/10.1080/1045988X.2011.539454

Spears, B., Slee, P. T., Owens, L., \& Johnson, B. (2009). Behind the Scenes and Screens: Insights into the Human Dimension of Covert and Cyberbullying. Zeitschrift für Psychologie/Journal of Psychology, 217, 189-196.

https://doi.org/10.1027/0044-3409.217.4.189

Styron, R., Bonner, J., Styron, J., Bridgeforth, J., \& Martin, C. (2016). Are Teacher and Principal Candidates Prepared to Address Student Cyberbullying? Journal of At-Risk Issues, 19, 19-28.

Ybarra, M. L., Diener-West, M., \& Leaf, P. J. (2007). Examining the Overlap in Internet Harassment and School Bullying: Implications for School Interventions. Journal of Adolescent Health, 41, 42-50. https://doi.org/10.1016/j.jadohealth.2007.09.004

Yoon, J. S., Bauman, S., Chou, T., \& Hutcinson, A. (2011). How South Korean Teachers Handle an Incident of School Bullying. School Psychology International, 32, 312-329. https://doi.org/10.1177/0143034311402311

Yorulmaz, Y., \& Altınkurt, Y. (2018). The Examination of Teacher Burnout in Turkey: A Meta-Analysis. Turkish Journal of Education, 7, 34-54. https://doi.org/10.19128/turje.348273

Zimmerman, B. J., Bandura, A., \& Martinez, M. (1992). Self-Motivation for Academic Attainment: The Role of Self-Efficacy Beliefs and Personal Goal-Settings. American Educational Research Journal, 29, 663-676. https://doi.org/10.3102/00028312029003663 